\title{
DETECTION OF GENETIC CHARACTERIZATION OF PORCINE CIRCOVIRUS 2 (PCV2) IN BRAZILIAN WILDLIFE BOARS
}

\author{
Castro, A.M.M.G. ${ }^{*}$; Castro Jr., F.G. ${ }^{2}$; Budiño, F.E.L. ${ }^{2}$; Baldin, C.M. ${ }^{1}$; Silva, S.O.S. ${ }^{1}$; Brandão, P.E. ${ }^{1}$; Richtzenhain, L.J. $^{1}$ \\ ${ }^{1}$ Departamento de Medicina Preventiva e Saúde Animal, Faculdade de Medicina Veterinária e Zootecnia, Universidade de São \\ Paulo, São Paulo, SP, Brasil; ${ }^{2}$ Departamento de Zootecnia Diversificada, Instituto de Zootecnia, Nova Odessa, SP, Brasil.
}

\begin{abstract}
A semi-intensive wildlife boars farm presented a clinical history of high mortality in 70 - 90 days-old pigs (> $50 \%$ ). Two 90 days-old animals with weight loss and wasting were necropsied and the samples tested for PCV2 by polymerase chain reaction (PCR). The genetic material of PCV2 was sequenced and classified into the PCV2a genotype together with PCV2 sequences obtained from samples of Poland, Brazil, Slovenia and Greece wild boars.
\end{abstract}

Key words: Porcine circovirus-2; wildlife boars pigs; phylogenetic analyses

Porcine circovirus-2 (PCV2), belongs to the Circovirus genus of the family Circoviridae and is associated with a number of syndromes defined as porcine circovirus associated diseases (PCVAD). The genome of PCV2, composed of DNA, which is circular and covalently closed, contains two major reading frames (ORF1 and 2) and some minor but not less important ORFs. ORF1 encodes the replicase and ORF2 encodes the capsid protein of approximately $30 \mathrm{kDa}(9)$.

The virus is recognized worldwide as endemic in commercial swine herds. Phylogenetically, PCV2 is divided into two major groups, PCV2a and PCV2b and the most distinct nucleotide differences between the two groups are found in the capsid protein (9). A third genotype (PCV2c) had been detected, recently, in Danish animals by Dupont (8). PCV2a and PCV2b are worldwide distributed and no association with pathogenicity has been found. In healthy herds in Sweden and Spain, PCV2b is the most prevalent genotype, whereas PCV2a more related to PMWS affected herds. However, in Switzerland, there was an association of PCV2b and the presence of disease in animals (13). In Brazil, both group were also detected and no relationship were observed between clinical signs and different genotypes of PCV2 (4).

These wildlife boars were initially introduced in different regions of Brazil with commercial explorations purpose to attend an alternative for the segment of exotic flavors of the meat market. However, over time, it proved to be commercially disadvantageous and these animals began to live into the wild being a significant reservoir of the disease. The prevalence of PCV2 in wildlife boars has been reported in different countries. The seroprevalence in Belgian and Spanish herds were from 30 to $40 \%$ (12). PCV2 infection was detected in about $20 \%$ of Hungarian wild boars using polymerase chain reaction (PCR)

*Corresponding Author. Mailing address: Departamento de Medicina Preventiva e Saúde Animal - Faculdade de Medicina Veterinária 10 e Zootecnia da Universidade de São Paulo.; Tel.: +55 1130917704 Fax: 55113091 7928.; E-mail: ammgcastro@usp.br 
(7). In Greece, there was a report stating that wild boars with wasting and dyspnea had died and PCV2 was detected in tissue samples and the histopathologic lesions were consistent with PMWS described in domestic pigs (10). In Brazil, a high (54.09\% to $89.53 \%$ ) prevalence was reported (2) indicating the importance of this virus in the wild boar population. In an effort to understand the PCV2 diversity, the purpose of this study was to phylogenetically characterize the genetic material of the virus detected from two Brazilian wildlife boars.

The clinical samples were collected from two 90 days-old wild boar pigs, with weight loss (medium weight $15 \mathrm{Kg}$ ) and wasting. The semi-intensive wild boars farm presented a clinical history of high mortality in $70-90$ days-old pigs (>50\%). The two pigs were necropsied and lymph nodes (mesenteric and inguinal) were collected. Macroscopically, an enlargment was observed of mesenteric and inguinal lymph nodes. Homogenates $(20 \% \mathrm{w} / \mathrm{v})$ of the samples were prepared and DNA extraction was carried out by guanidine isothiocyanate/glycogen method described by Chomkzynski (6).

The detection of PCV2 was performed by PCR using primers Fa (5' ATT ACC AGC AAT CAG ACC CCG T 3')/Ra (5' CAA CCC TTC TCC TAC CAC TCC 3') that amplify a 476 bp fragment from ORF1 and ORF2 (position 807-1282 nt). For each enzymatic reaction, $5 \mu \mathrm{L}$ of DNA was added to a PCR mixture with final concentrations of $1.25 \mathrm{mM} \mathrm{MgCl} 2,1$ x PCR buffer, 1.25 U Taq DNA polymerase, $0.2 \mathrm{mM}$ each dNTP and $50 \mathrm{pmol}$ of each primers. Amplification was performed in a thermocycler with the following conditions: $95{ }^{\circ} \mathrm{C}$ for 5 minutes, 39 cycles with 95 ${ }^{\circ} \mathrm{C}$ for 1 minute, $60{ }^{\circ} \mathrm{C}$ for 1 minute and $72{ }^{\circ} \mathrm{C}$ for 1 minute and $72^{\circ} \mathrm{C}$ for 10 minutes (4).

The samples of the two animals were positive for PCV2 and the complete PCV2 genome was sequenced from the two samples using four pairs of primers described by An (1). Amplicons with the expected molecular sizes, which were $700 \mathrm{bp}, 630 \mathrm{bp}, 705 \mathrm{bp}$ and $700 \mathrm{bp}$ for P1/P2, P3/P4, P5/P6 and P7/P8, respectively, were excised from the $1.5 \%$ agarose gel and purified using a commercial kit (Concert, Gibco-BRL ${ }^{\mathrm{TM}}$ ). Bi-directional sequencing reactions were performed using BigDyeTM Terminator v3.1 (Applied Biosystems ${ }^{\mathrm{TM}}$ ) and run using ABI model 377 sequencer analyzer (ABI model 377, Applied
BiosystemsTM). The consensus sequence assembling was done using the PHRED/PHRAP and CAP3 (http://bioinformatica. ucb.br/electro.html) program with an analyses quality point of 20 .

The obtained sequences were aligned with sequences from GenBank using CLUSTAL X software (11). The phylogenetic analyses were done using the complete sequence or partial sequences of ORF2 depending on the availability of the sequences in GenBank was performed on the aligned data set, and a rooted tree was constructed in Mega v.2.1 using the distance-based neighbour-joining method with the PCV1 sequence as an outgroup.

The genome sequence of the two strain (BRA_JAV1_2008 and BRA_JAV2_2008) recovered were of 1,767 nt, which shared a nucleotide and aminoacid identity of $100 \%$. The phylogenetic tree analyses classified the two strain of this study in PCV2a subgroup together with PCV2 sequences of strain from wild boars from Poland, Brazil, Slovenia and Greece.

The results confirmed that the virus is circulating within the Brazilian the wildlife boar herd, as showed previously by serological analysis (2) and it could be probably involved in the increase in the mortality rates observed in growing pigs in the herd. In the present case, the inadequate management, which was overpopulation, mixing pigs and failure on use of the all in/all out systems in the growing phase and in the herd was an essential factor in disease outcome. The improvement of this management reduced the mortality rates after 60 days. The detection of PCV2 in wildlife boar has been related in Europe and also in others Brazilian state $(2,7,12)$. However, to confirm the association of PCV2 with the clinical signs, others tests, such as immunohistochemistry and histopathological analysis should be used. The detection of PCV2 by PCR is a indicative that the virus is circulating in the wild boar herd and that it could be one of the factors involved in the increase in the mortality rates observed in growing phase.

The BRA_JAV1_2008 and BRA_JAV2_2008 sequences recovered were $1,767 \mathrm{bp}$ long and lack the insertion of 11 nucleotides observed at position 42 , nine bases upstream from the initiation codon of ORF1, which was also observed in sequences previously reported by Boisseson (3) and Dupont (8).

The phylogenetic tree analyses classified the two strain of 
this study in PCV2a together with PCV2 sequences of strain from wild boars from previous reports. Unlike what was observed with the sequences from Germany, Slovenia and Poland, which are distributed in both groups (PCV2a and PCV2b), the strain of this study are grouped in PCV2a (Figure 1). This can be related to the year in which the sample was collected, since strain of PCV2b genotype were only detected in Brazil prior to 2005 (4,5). Dupont
(8) also reported the association of year of detection with the PCV2 genotype, since the authors demonstrated that PCV2a is detected in more recent samples when compared with PCV2b and PCV2c. There were no differences in the grouping of strain when used at total (data not shown) or partial sequence of the genome (ORF2), indicating, as observed by Olvera (9), that ORF2 is a good region for genetic analyses.

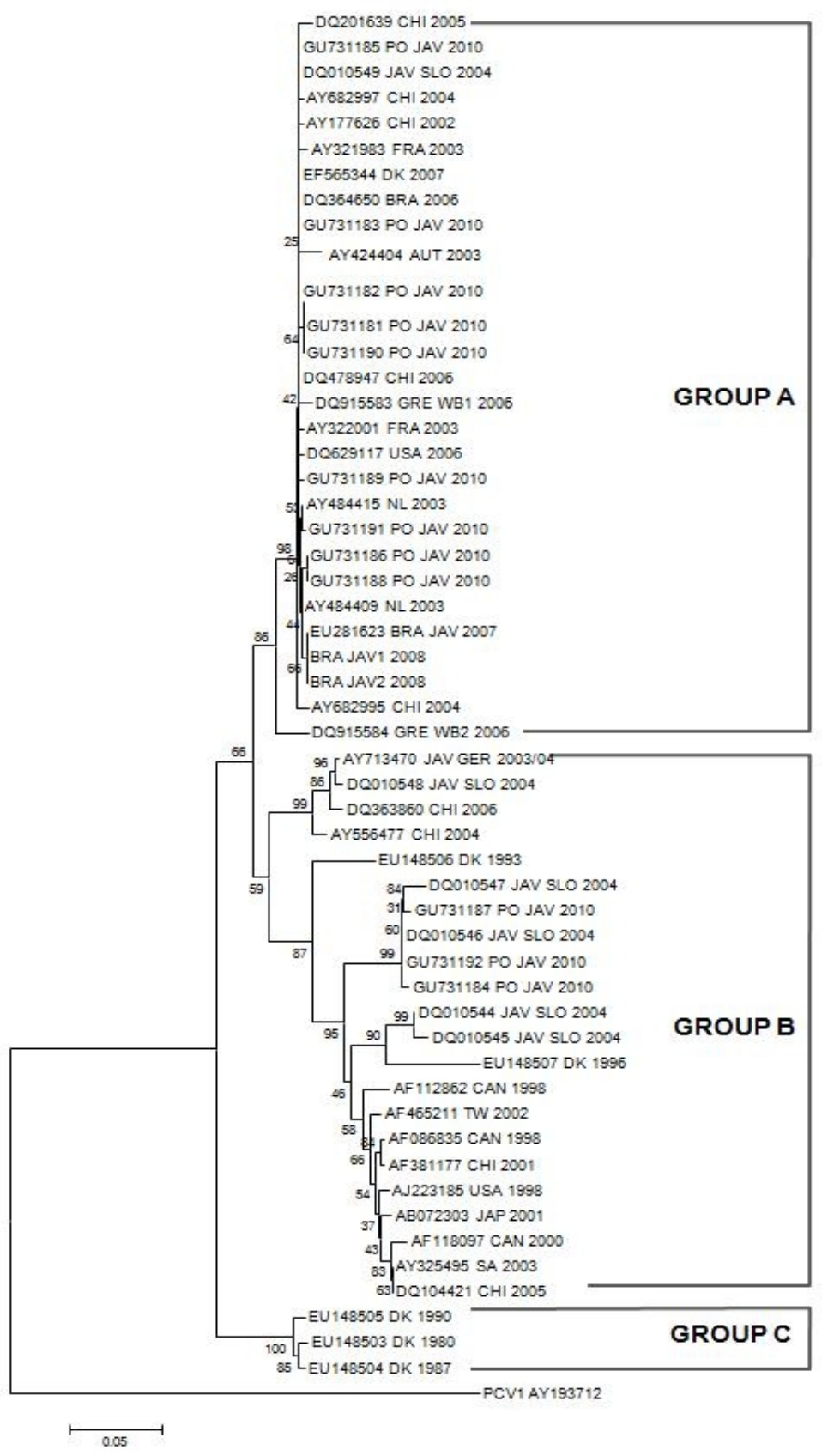

Figure 1. Neighbor-Joining phylogenetic tree of the complete genome of PCV2 sequences from various countries. A rooted phylogenetic tree was constructed by the neighbor-joining (NJ) method from aligned sequences constructed by: one PCV1 sequence as out-group; 51 PCV2 sequences from the GenBank; and the two sequences from the present study (BRA_JAV1_2008; BRA_JAV2_2008). The bootstrap value (1000 replicates) for each clade is shown. 
This is the first complete sequence and characterization of PCV2 detected in wildlife boar in Brazil. Despite the small number of samples, the phylogenetic analyses demonstrated that the same PCV2 genotype is circulating in wild and domestic pigs in Brazil. However, further investigations are needed to better understand the epidemiological role of wild boars in the transmission of PCV2, in particular as a potential reservoir for the populations of domestic swine living in the same geographical area.

\section{REFERENCES}

1. An, D.J.; Roh, I.S.; Song, D.S.; Park, C.K.; Park, B.K. (2007). Phylogenetic characterization of porcine circovirus type 2 in PMWS and PDNS Korean pigs between 1999 and 2006. Virus Research 129,115122

2. Barbosa, N.; Lobato, Z.I.P.; Freitas, T.R.; Ciacci-Janella, J.R.; Ristow, L.E. (2006). Prevalence of the porcine circovirus type 2 (PCV2) in wild boars (Sus scrofa) in Brazil. In: Proceedings of the 19th IPVS Congress. Copenhagen, Denmark. 2:90.

3. Boisseson, C.; Beven, V.; Bigarre, L.; Thiéry, R.; Rose, N.; Eveno, E.; Madec, F.; Jestin, A. (2004). Molecular characterization of Porcine circovirus type 2 isolates from post-weaning ultisystemic wasting syndrome-affected and non-affected pigs. J. Gen. 125 Virol. 85, 293304.

4. Castro, A.M.M.G.; Cortez, A.; Heinemann, M.B.; Brandão, P.E.; Richtzenhain, L.J. (2007). Genetic diversity of Brazilian strains of porcine circovirus type 2 (PCV2) revealed by analysis of the cap gene (ORF-2). Arch. Virol. 152, 1435-1445.

5. Chiarelli-Neto, O.; Yotoki, K.S.; Vidigal, P.M.P.; Silva, F.M.F.; Castro,
L.A; Fietto, J.L.R.; Silva, Jr. A.; Almeida, M.R. (2008). Classification and putative origins of Brazilian porcine circovirus 2 inferreSilvad through phylogenetic and phylogeographical approaches. Virus Research 140, 57-63.

6. Chomkzynski, P. (1993). A reagent for the single step simultaneous isolation of RNA, DNA and proteins from cells and tissue samples. Biotechniques 15:532-537.

7. Cságola, A.; Kecskemeti, S.; Kardos, G.; Kiss, I.; Tuboly, T. (2006). Genetic characterization of type 2 porcine circoviruses detected in Hungarian wild boar. Arch. Virol. 151, 495-507.

8. Dupont, K.; Nielsen, E.O.; Baekbo, P.; Larsen, L.E. (2008). Genomic analysis of PCV2 isolates from Danish archives and a current PMWS case-control study supports a shift in genotypes with time. Vet. Microbiol. 128, 56-64.

9. Olvera, A.; Cortey. M.; Segales, J. (2007). Molecular evolution of porcine circovirus type 2 genomes: Phylogeny and clonality. Virology $357,175-85$.

10. Sofia, M.; Billinis, C.; Psychas, V.; Birtsas, P.; Sofianidis, G.; Leontides, L.; Knowles, N.; Spyrou, V. (2008). Detection and genetic characterization of porcine circovirus 2 isolates from the first cases of postweaning multisystemic and wasting syndrome in wild boars in Greece. J. Wildlife Dis. 44, 864-70.

11. Thompson, J.D.; Gibson, T.J.; Plewniak, F. (1997). The CLUSTAL X windows interface: flexible strategies for multiple sequence alignment aided by quality analysis tools. Nucl. Acids Res. 25, 4876-82.

12. Vicente, J.; Segales, J.; Hofle, U. (2004). Epidemiological study on porcine circovirus type 2 (PCV2) infection in the European wild boar (Sus scrofa). Vet. Res. 35, 150 243-53.

13. Wiederkehr, D.D.; Sydler, T.; Buergi, E.; Haessig, M.; Zimmermann, D.; Pospischil, A.; Brugnera, E.; Sidler, X. (2009). A new emerging genotype subgroup within PCV-2b dominates the PMWS epizooty in Switzerland. Vet. Microbiol. 136, 27-35. 